\title{
Reclassification of Vibrio fischeri, Vibrio logei, Vibrio salmonicida and Vibrio wodanis as Aliivibrio fischeri gen. nov., comb. nov., Aliivibrio logei comb. nov., Aliivibrio salmonicida comb. nov. and Aliivibrio wodanis comb. nov.
}

\section{Correspondence Paul V. Dunlap pvdunlap@umich.edu}

\author{
Henryk Urbanczyk, ${ }^{1}$ Jennifer C. Ast, ${ }^{1}$ Melissa J. Higgins, ${ }^{2}$ Jeremy Carson ${ }^{2}$ \\ and Paul V. Dunlap ${ }^{1}$ \\ ${ }^{1}$ Department of Ecology and Evolutionary Biology, University of Michigan, Ann Arbor, \\ Ml 48109-1048, USA
${ }^{2}$ The Tasmanian Aquaculture and Fisheries Institute, University of Tasmania, Launceston, Tasmania, Australia

\begin{abstract}
Four closely related species, Vibrio fischeri, Vibrio logei, Vibrio salmonicida and Vibrio wodanis, form a clade within the family Vibrionaceae; the taxonomic status and phylogenetic position of this clade have remained ambiguous for many years. To resolve this ambiguity, we tested these species against other species of the Vibrionaceae for phylogenetic and phenotypic differences. Sequence identities for the $16 \mathrm{~S}$ rRNA gene were $\geqslant 97.4 \%$ among members of the $V$. fischeri group, but were $\leqslant 95.5 \%$ for members of this group in comparison with type species of other genera of the Vibrionaceae (i.e. Photobacterium and Vibrio, with which they overlap in $\mathrm{G}+\mathrm{C}$ content, and Enterovibrio, Grimontia and Salinivibrio, with which they do not overlap in $\mathrm{G}+\mathrm{C}$ content). Combined analysis of the $\operatorname{rec} A, r p o A, p y r H, g y r B$ and $16 \mathrm{~S}$ rRNA gene sequences revealed that the species of the $V$. fischeri group form a tightly clustered clade, distinct from these other genera. Furthermore, phenotypic traits differentiated the $V$. fischeri group from other genera of the Vibrionaceae, and a panel of 13 biochemical tests discriminated members of the $V$. fischeri group from type strains of Photobacterium and Vibrio. These results indicate that the four species of the $V$. fischeri group represent a lineage within the Vibrionaceae that is distinct from other genera. We therefore propose their reclassification in a new genus, Aliivibrio gen. nov. Aliivibrio is composed of four species: Aliivibrio fischeri comb. nov. (the type species) (type strain

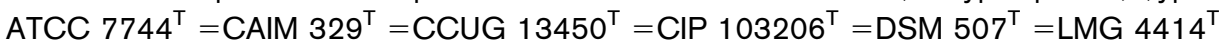
$=$ NCIMB $1281^{\top}$ ), Aliivibrio logei comb. nov. (type strain ATCC $29985^{\top}=$ CCUG $20283^{\top}=\mathrm{CIP}$ $104991^{\top}=$ NCIMB $2252^{\top}$ ), Aliivibrio salmonicida comb. nov. (type strain ATCC $43839^{\top}=$ CIP $103166^{\top}=$ LMG $14010^{\top}=$ NCIMB $2262^{\top}$ ) and Aliivibrio wodanis comb. nov. (type strain

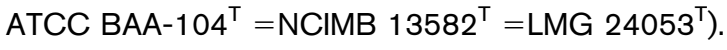

The family Vibrionaceae consists of a large number of ecologically diverse species (Farmer et al., 2005). Members of this family are relatively easy to culture and common in marine environments, and several species are important animal pathogens. Understanding the ecology and evolution of the Vibrionaceae requires a taxonomy that

The GenBank/EMBL/DDBJ accession numbers for the sequences obtained in this study are EF380230-EF380261, EF667054 and EF667055, as detailed in Fig. 1.

GenBank accession numbers for $16 \mathrm{~S}$ rRNA gene sequences and a table with complete phenotyping data are available as supplementary material with the online version of this paper. accurately reflects intrafamilial species relationships; however, a number of groups in the Vibrionaceae remain indefinitely resolved (Farmer et al., 2005). One of these groups is the Vibrio fischeri group, which contains four species, Vibrio fischeri (Beijerinck, 1889), Vibrio logei (Harwood et al., 1980), Vibrio salmonicida (Egidius et al., 1986) and Vibrio wodanis (Lunder et al., 2000). Previous taxonomic studies have shown that these four species are closely related to each other, but there is disagreement about the genus into which these species should be classified (Thyssen \& Ollevier, 2005). Some analyses of $V$. fischeri, for example, have identified phenotypic traits (Reichelt \& Baumann, 1973) or molecular characters 
(Baumann \& Baumann, 1977) consistent with membership in Photobacterium, whereas other studies have placed $V$. fischeri in Vibrio based on other phenotypic traits (Hendrie et al., 1970) or on polyphasic analysis of phenotypic and molecular characteristics (Baumann et al., 1980). Recently, Thompson et al. (2005) suggested that the Vibrionaceae should be divided into four families, with the placement of $V$. fischeri, $V$. logei and $V$. wodanis in an unnamed monophyletic group, sister to the Vibrionaceae (which the authors suggest should consist only of genus Vibrio) and separate from the family 'Photobacteriaceae'. The ambiguity of the taxonomy and phylogenetic placement of the V. fischeri group is reflected in current species naming. Photobacterium fischeri and Photobacterium logei are synonyms of $V$. fischeri and $V$. logei, although the two species have characteristics more similar to those of $V$. wodanis and $V$. salmonicida than to those of Photobacterium phosphoreum, the type species of Photobacterium, whereas neither $V$. wodanis nor $V$. salmonicida has been considered to be a member of Photobacterium. The conflicting concepts regarding classification of the $V$. fischeri group indicate the need to resolve the relationship of this group relative to other species in the Vibrionaceae. The importance of a more definitive resolution of groups currently classified in Vibrio is especially evident with the advent of genome sequence analysis and subsequent attempts to interpret differences between pathogenic and non-pathogenic species in a systematic context (e.g. Ruby et al., 2005).

In this study, we tested the ability of genetic loci and phenotypic traits to distinguish members of the $V$. fischeri group from representatives of Vibrio, Photobacterium and other genera in the family. Based on the results, which demonstrate that the $V$. fischeri group is distinct phylogenetically and phenotypically from other genera in the Vibrionaceae, we propose the establishment of a new genus, Alivibrio gen. nov., for the members of the $V$. fischeri group.

First, we determined the extent of 16S rRNA gene sequence identity between members of the $V$. fischeri group and representative species of Enterovibrio, Grimontia, Photobacterium, Salinivibrio and Vibrio. Despite the importance of the $16 \mathrm{~S}$ rRNA gene for bacterial taxonomy, special care is required for its use in taxonomy of the Vibrionaceae. Several loop regions of the 16S rRNA gene have highly variable sequences and are difficult to align objectively; at the same time, stem regions are sometimes invariant between different species. To minimize difficulties associated with 16S rRNA gene sequence comparison, we used direct optimization (Wheeler, 1996) for alignment of sequences, as implemented by the program POY (version 4.0 beta build 1822) (Varón et al., 2007). The direct optimization method iteratively evaluates alignments in a phylogenetic context, and this method of analysis results in a more rigorously tested alignment; it is therefore an improvement over other alignment programs and is especially useful for sequences like those of 16S rRNA genes in which insertion-deletion events are common and result in length differences among homologous sequences. For the analysis, we compared 16S rRNA gene sequences of 92 type strains from the Vibrionaceae, including the type strains of the four species of the $V$. fischeri group. Accession numbers of the 16S rRNA gene sequences used here can be found in Supplementary Table S1, available in IJSEM Online. For direct optimization, gap and nucleotide change costs were set to 1 [using the command transform((all, tcm:(1,1)))]. Ten initial trees were built using random addition sequence $[$ build()]. Each starting tree was subjected to branch swapping, alternating subtree pruning-regrafting and tree bisection-reconnection [swap ()]. After 20 replicates, the shortest three trees were kept [select(best:3)] and submitted to tree fusing [fuse()] and to 100 iterations of parsimony ratcheting, with reweighting $20 \%$ of the characters [transform((all, static_approx $)$ )] by 5 and keeping up to five trees [perturb(iterations:100, ratchet:(0.2,5), swap(trees:5))]. Tree fusing and ratcheting independently found the same shortest phylogenetic hypothesis and alignment, with an alignment length of 1397 characters (the resulting alignment and tree are available from the authors on request). After the alignment was constructed, pairwise distances between 16S rRNA gene sequences were calculated in PAUP (Swofford, 2003) using the Kimura two-parameter model.

High sequence identities, of $97.4 \%$ or more, were obtained for the 16S rRNA genes of the $V$. fischeri group (Table 1), indicating a close relationship among these strains. In contrast, 16S rRNA gene sequence identities between type strains of species in the $V$. fischeri group and other species of the Vibrionaceae were consistently lower. Specifically, sequence identities for $V$. fischeri ATCC $7744^{\mathrm{T}}$ and $P$. phosphoreum ATCC $11040^{\mathrm{T}}$ (the type species of Photobacterium) and Vibrio cholerae ATCC $14035^{\mathrm{T}}$ (the type species of Vibrio) are 95.4 and $94.6 \%$, respectively. The 16S rRNA gene sequence identities of $V$. fischeri ATCC $7744^{\mathrm{T}}$ to type strains of type species of other genera in the family were below $92.3 \%$. These results indicate that, based on $16 \mathrm{~S}$ rRNA gene sequence identities, the four species of the $V$. fischeri group form a group within the Vibrionaceae that is distinct from other species in the family.

As a complement to analysis of the $16 \mathrm{~S}$ rRNA gene, we next carried out a multilocus sequence analysis to gain insight into the phylogenetic relationship between the $V$. fischeri group and species of Enterovibrio, Grimontia, Photobacterium, Salinivibrio and Vibrio. Emphasis was placed on species of Vibrio and Photobacterium, to which the members of the $V$. fischeri group exhibit greater similarity. For the analysis, we used sequences of three housekeeping genes, recA, rpoA and $p y r H$, recommended by Thompson et al. (2005) for Vibrionaceae phylogeny, together with gyrB, the sequence of which discriminates species in the Vibrionaceae (Ast \& Dunlap, 2005), and sequences of the $16 \mathrm{~S}$ rRNA gene. These genes were analysed simultaneously using type strains of 43 representative species of the Vibrionaceae, including representatives of the five 
Table 1. Pairwise comparison of $16 \mathrm{~S}$ rRNA gene sequence identities between representative strains of the Vibrionaceae

Values are percentage similarity. Values in bold are sequence identities among strains of Aliivibrio gen. nov. 16S rRNA gene sequence identity comparisons for the full set of 92 strains examined in this study are available from the authors on request.

\begin{tabular}{|c|c|c|c|c|c|c|c|c|c|c|c|c|c|c|}
\hline Strain & 1 & 2 & 3 & 4 & 5 & 6 & 7 & 8 & 9 & 10 & 11 & 12 & 13 & 14 \\
\hline \multicolumn{15}{|l|}{ Aliivibrio gen. nov. } \\
\hline 1. A. fischeri ATCC $7744^{\mathrm{T}}$ & - & - & - & - & - & - & - & - & - & - & - & - & - & - \\
\hline 3. A. salmonicida ATCC $43839^{\mathrm{T}}$ & 97.4 & 99.4 & - & - & - & - & - & - & - & - & - & - & - & - \\
\hline 4. A. wodanis ATCC BAA- $104^{\mathrm{T}}$ & 98.5 & 98.6 & 98.1 & - & - & - & - & - & - & - & - & - & - & - \\
\hline \multicolumn{15}{|l|}{ Enterovibrio } \\
\hline \multicolumn{15}{|l|}{ Grimontia } \\
\hline 7. G. hollisae ATCC $33564^{\mathrm{T}}$ & $91.1^{\star}$ & 91.7 & 91.5 & 91.8 & 95.9 & 95.3 & - & - & - & - & - & - & - & - \\
\hline \multicolumn{15}{|l|}{ Photobacterium } \\
\hline 8. P. phosphoreum ATCC $11040^{\mathrm{T}}$ & $95.4^{\star}$ & 95.2 & 95.0 & 95.5 & 93.0 & 93.7 & 92.5 & - & - & - & - & - & - & - \\
\hline 9. P. profundum JCM $10084^{\mathrm{T}}$ & 95.0 & 95.1 & 94.9 & 95.9 & 93.3 & 93.2 & 93.6 & 96.0 & - & - & - & - & - & - \\
\hline 12. V. cholerae ATCC $14035^{\mathrm{T}}$ & $94.6^{*}$ & 93.3 & 93.0 & 93.7 & 93.0 & 92.6 & 91.6 & 93.0 & 92.9 & 90.2 & 90.0 & - & - & - \\
\hline 13. V. harveyi ATCC $14126^{\mathrm{T}}$ & 94.7 & 95.2 & 95.0 & 95.6 & 93.2 & 93.5 & 92.8 & 94.2 & 94.6 & 90.8 & 90.5 & 94.4 & - & - \\
\hline 14. V. splendidus ATCC $33125^{\mathrm{T}}$ & 96.0 & 96.4 & 96.1 & 96.0 & 92.6 & 92.8 & 91.8 & 94.3 & 93.9 & 90.9 & 90.8 & 94.1 & 96.3 & - \\
\hline
\end{tabular}

${ }^{\star} 16 \mathrm{~S}$ rRNA gene identities between A. fischeri (the type species of Aliivibrio) and type species of other genera of the Vibrionaceae.

well-characterized genera in the family. Because inclusion of additional taxa improves phylogenetic analysis (Graybeal, 1998; Hillis, 1998), we also included sequence data for $V$. fischeri strains ES114 (from the light organ of the sepiolid squid Euprymna scolopes; Ruby et al., 2005), MJ-1 (from the light organ of the monocentrid fish Monocentris japonicus; Ruby \& Nealson, 1976), etasm.1.1 (from the light organ of the sepiolid squid Euprymna tasmanica; this study) and lpeal.1.1 (from the accessory nidamental gland of the loliginid squid Loligo pealei; this study) and for $V$. salmonicida strain LFI1238 (http:// www.sanger.ac.uk/Projects/V_salmonicida/). As outgroup in the analysis, we used Photorhabdus luminescens subsp. laumondii $\mathrm{TT}^{\mathrm{T}} \mathrm{1}^{\mathrm{T}}$ (Duchaud et al., 2003), giving a total of 49 strains. PCR amplifications were done as described previously (Thompson et al., 2005; Ast \& Dunlap, 2005) except for $p y r H$, for which primer PBPRA2966Rv (5'GAATCGGCATTTTATGGTCACG-3') was used instead of pyrH-02-R. Sequencing was done by staff of the University of Michigan Sequencing Core using dye-terminator cycle sequencing on a Perkin-Elmer ABI 3730 or 3700 DNA Analyzer. Gene sequences from the five loci were concatenated and used for direct optimization analysis. Gaps and nucleotide changes were set to 1 for the $16 \mathrm{~S}$ rRNA gene, as they were in the analysis of percentage sequence identity of the $16 \mathrm{~S}$ rRNA gene. For the four protein-coding genes, initial gap costs were set to 2 , with extension gaps and nucleotide change costs set to 1 . Analysis proceeded as described above for the 16S rRNA gene (except for the use of 35 replicates of builds and swapping instead of the 20 replicates used in the 16S rRNA gene analysis and $20 \%$ of fragments, instead of characters, were reweighted in the ratchet). A single, shortest hypothesis was found after fusing and ratcheting (see legend to Fig. 1 for tree statistics). Confidence values were obtained with 10000 jackknife resampling replicates (Farris et al., 1996) using TNT (Goloboff et al., 2005).

The analysis revealed a distinct separation, with high jackknife support values, between species of the $V$. fischeri group and members of other genera in the Vibrionaceae (Fig. 1). The $V$. fischeri group forms a clade closely related to Photobacterium and Vibrio but clearly separate from both these genera and more distantly related to other genera of the Vibrionaceae. We note parenthetically here also that these relationships accord with the overlap in $\mathrm{G}+\mathrm{C}$ contents between the $V$. fischeri group and Photobacterium and Vibrio and the lack of overlap in these values between the $V$. fischeri group and Enterovibrio, Grimontia and Salinivibrio (see Table 2). These results, which are consistent with the percentage identities in $16 \mathrm{~S}$ rRNA gene sequences (Table 1), indicate that the members of the $V$. fischeri group form a phylogenetic lineage of the Vibrionaceae that is distinct from Photobacterium, Vibrio and other genera in the family.

To test this result, we next asked whether the members of the $V$. fischeri group could be distinguished from other genera of the Vibrionaceae by phenotypic criteria. A panel 


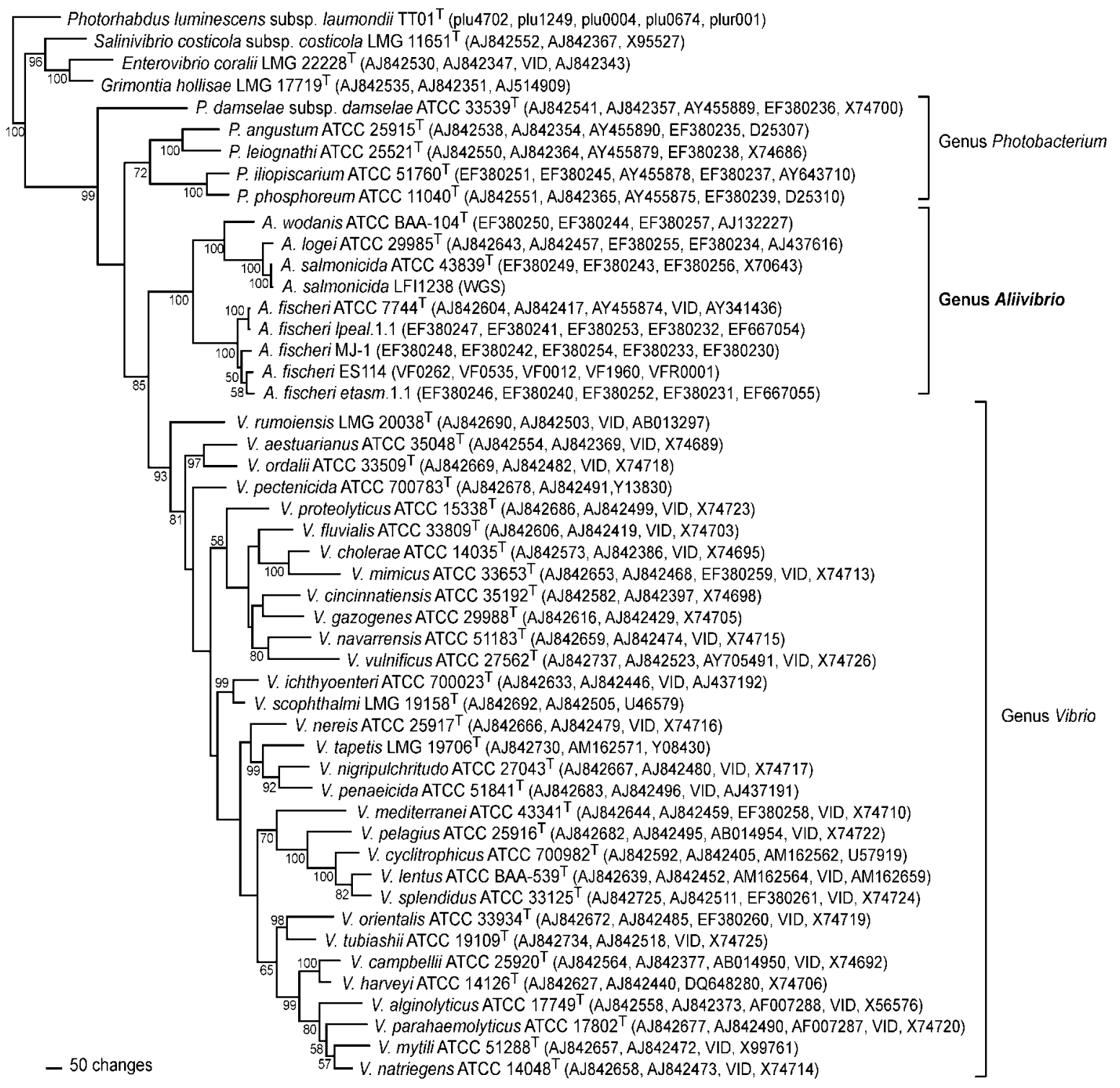

Fig. 1. Phylogenetic resolution of Aliivibrio gen. nov. from other genera of the Vibrionaceae. For the analysis, sequences of five genes, gyrB, rpoA, recA, pyrH and the 16S rRNA gene, were concatenated and then aligned, giving a total of 4868 aligned characters (1539 phylogenetically informative characters). The analysis resulted in a single most-parsimonious tree. Tree length $=9824$, consistency index $=0.480$, retention index $=0.570$. Jackknife values are reported at nodes. See text for methodological details. Accession numbers for sequences used in the analysis are given in parentheses. Sources of sequences other than GenBank/EMBL/DDBJ are indicated as follows: VID, MLSA identification page for Vibrionaceae (http:// www.taxvibrio.Incc.br); WGS, A. salmonicida LFI1238 whole-genome sequencing project (http://www.sanger.ac.uk/ Projects/V_salmonicida/). For $A$. fischeri ES114 and P. luminescens subsp. laumondii $\mathrm{TTO}^{\top}{ }^{\top}$, locus tags assigned during whole-genome sequencing projects are given (see NC_006840 and NC_006841, and NC_005126, respectively, at http:// www.ncbi.nlm.nih.gov/sites/entrez?db=Genome).

of 46 standardized biochemical tests, discriminatory for species of the Vibrionaceae (Carson et al., 2006; see references cited in Supplementary Table S2 for test methods), was used. Several of these tests were found to distinguish the $V$. fischeri group from other genera in the Vibrionaceae (Table 2). Furthermore, a panel of 13 tests was identified that differentiated species within the $V$. fischeri group from each other and from species of Photobacterium and Vibrio, the two genera most closely related to the $V$. fischeri group (Table 3 ). For this specieslevel analysis, strains used in the multilocus phylogenetic analysis (Fig. 1), together with type strains of six 
Table 2. Traits that differentiate Aliivibrio gen. nov. from other genera of Vibrionaceae

Genera: 1, Aliivibrio; 2, Enterovibrio; 3, Grimontia; 4, Photobacterium; 5, Salinivibrio; 6, Vibrio. Data for Enterovibrio and Salinivibrio were obtained from Thompson et al. (2002) and Huang et al. (2000). +, $\geqslant 75 \%$ of species positive; -, $<25 \%$ of species positive; d, different reactions given by different species.

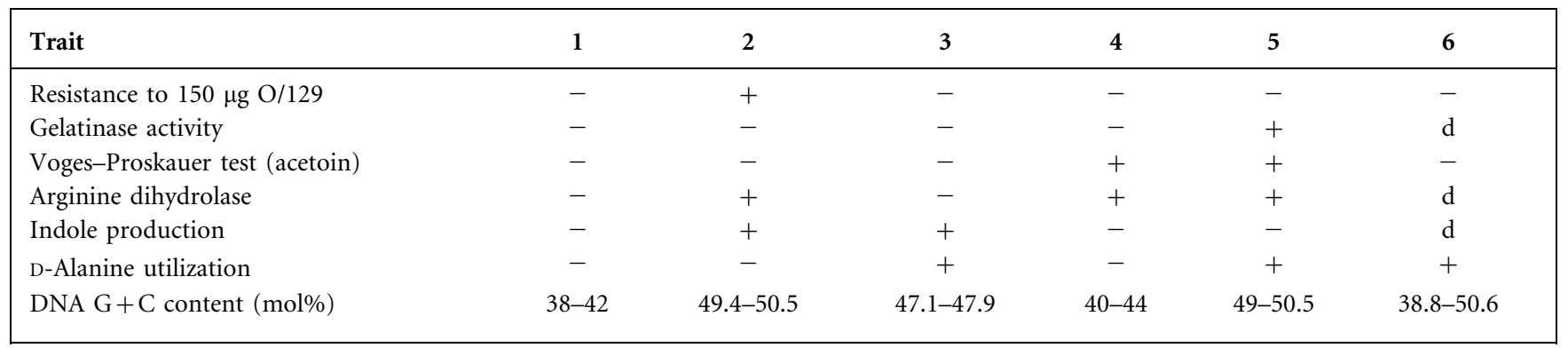

Photobacterium species and 32 Vibrio species and additional strains of $V$. fischeri, were examined. Discriminatory tests were identified using the GBEST algorithm, part of the PIBWin suite of tools for probabilistic identification of bacteria (Bryant, 1991, 2004). All taxa could be differentiated by at least two tests with a test difference $\geqslant 70 \%$ (Willcox et al., 1973) (Table 3; complete results for all 46 tests can be found in Supplementary Table S2). The results of these phenotypic comparisons are consistent with the differences revealed by the $16 \mathrm{~S}$ rRNA gene sequence identity comparison and by the multilocus phylogenetic analysis of the recA, rpoA, pyrH, gyrB and 16S rRNA genes.

Based on these results, we propose the establishment of a new genus, Alivivibrio gen. nov., to accommodate Vibrio fischeri, Vibrio logei, Vibrio salmonicida and Vibrio wodanis, and we propose the reclassification of these species as Aliivibrio fischeri comb. nov. (the type species), Aliivibrio logei comb. nov., Aliivibrio salmonicida comb. nov. and Alivibrio wodanis comb. nov., respectively.

\section{Description of Aliivibrio gen. nov.}

Aliivibrio (A.li.i.vib'ri.o. L. n. alius other, another; N.L. masc. n. Vibrio a bacterial genus name; N.L. masc. n. Aliivibrio the other Vibrio).

Gram-negative, motile, rod-shaped cells with one or more sheathed flagella. Conforms to the description of the family Vibrionaceae. Some strains are luminous. Oxidase-positive, fermentative and can utilize glucose as a sole carbon source; sensitive to the vibriostatic agent $\mathrm{O} / 129$ at $10 \mu \mathrm{g}$. Grow on media with $1 \%(\mathrm{w} / \mathrm{v}) \mathrm{NaCl}$ but not with $10 \%(\mathrm{w} /$ v) $\mathrm{NaCl}$. Species are arginine dihydrolase-negative, do not hydrolyse gelatin, do not form acetoin (Voges-Proskauer test) and are sensitive to novobiocin at $5 \mu \mathrm{g}$. Alivivibrio fischeri ferments gentiobiose and is urease-positive; all other species of the genus are negative for these two characteristics. All species utilize acetate as a sole carbon source except $A$. fischeri. Species other than A. salmonicida have yellow-orange cell-associated pigment. DNA G $+\mathrm{C}$ content is between 38 and $42 \mathrm{~mol} \%$. Found in the marine environment, often associated with animals; some species are mutualistic symbionts or pathogens of marine animals. Member of the Gammaproteobacteria. The type species is Aliivibrio fischeri.

\section{Description of Aliivibrio fischeri (Beijerinck 1889) comb. nov.}

Basonym: Vibrio fischeri (Beijerinck 1889) Lehmann and Neumann 1896.

Other synonym: Photobacterium fischeri (Beijerinck 1889) Reichelt and Baumann 1973.

The description is the same as that given for Photobacterium fischeri by Reichelt \& Baumann (1973) with the following additions. Negative for the VogesProskauer (acetoin) test, indole production, gelatinase and agarolysis. Urease-positive. Resistant to carbenicillin $(100 \mu \mathrm{g})$ and ampicillin $(10 \mu \mathrm{g})$. The type strain is ATCC $7744^{\mathrm{T}}=$ CAIM $329^{\mathrm{T}}=$ CCUG $13450^{\mathrm{T}}=$ CIP $103206^{\mathrm{T}}$ $=\operatorname{DSM} 507^{\mathrm{T}}=$ LMG $4414^{\mathrm{T}}=$ NCIMB $1281^{\mathrm{T}}$.

\section{Description of Aliivibrio logei (Harwood et al. 1980) comb. nov.}

Basonym: Photobacterium logei (ex Bang et al. 1978) Harwood et al. 1980.

Other synonym: Vibrio logei (Harwood et al. 1980) Baumann et al. 1981.

The description is the same as that given for Photobacterium logei by Bang et al. (1978) with the following additions. Indole-negative. Resistant to carbenicillin $(100 \mu \mathrm{g})$ and ampicillin $(10 \mu \mathrm{g})$ and sensitive to novobiocin $(5 \mu \mathrm{g})$. The type strain is ATCC $29985^{\mathrm{T}}$ $=$ CCUG $20283^{\mathrm{T}}=$ CIP $104991^{\mathrm{T}}=$ NCIMB $2252^{\mathrm{T}}$.

\section{Description of Aliivibrio salmonicida (Egidius et al. 1986) comb. nov.}

Basonym: Vibrio salmonicida Egidius et al. 1986. 
Table 3. Phenotypic traits that differentiate species of Aliivibrio gen. nov., Photobacterium and Vibrio

Tests: 1 , arginine dihydrolase; 2 , growth on $10 \% \mathrm{NaCl}$; 3, indole production; 4, $\alpha$-D-galactosidase (4-nitrophenyl $\alpha$-D-galactopyranoside); 5 , $\gamma$ glutamyl transpeptidase (L-glutamic acid 5-(4-nitroanilide); 6, aesculin hydrolysis; 7, $\alpha$-ketoglutarate utilization (as sole carbon and energy source); 8 , galactose utilization; 9, gluconate utilization; 10, propionate utilization; 11, sucrose utilization; 12 , ampicillin resistance (10 $\mu \mathrm{g}$ ); 13 , lysine decarboxylase. For the five tested A. fischeri strains (ATCC $7744^{\mathrm{T}}$, ES114, MJ-1, lpeal.1.1 and etasm.1.1), the percentage of strains giving a positive result is reported. +, Positive; -, negative; ND, not determined. Each test was performed twice, with the same result obtained each time. For test methods see Carson et al. (2006) or Supplementary Table S2.

\begin{tabular}{|c|c|c|c|c|c|c|c|c|c|c|c|c|c|}
\hline $\operatorname{Strain}(s)$ & 1 & 2 & 3 & 4 & 5 & 6 & 7 & 8 & 9 & 10 & 11 & 12 & 13 \\
\hline A. fischeri (5 strains) & 0 & 0 & 0 & 0 & 80 & 100 & 0 & 80 & 0 & 0 & 20 & 100 & 40 \\
\hline A. logei ATCC $29985^{\mathrm{T}}$ & - & - & - & - & + & + & + & + & + & - & - & + & + \\
\hline A. salmonicida ATCC $43839^{\mathrm{T}}$ & - & - & - & - & - & - & - & + & + & - & + & + & - \\
\hline A. wodanis ATCC BAA- $104^{\mathrm{T}}$ & - & - & + & - & - & - & - & - & - & - & + & - & - \\
\hline P. angustum ATCC $25915^{\mathrm{T}}$ & - & - & - & - & - & $\mathrm{ND}$ & + & + & - & - & - & + & + \\
\hline P. damselae subsp. damselae ATCC $33539^{\mathrm{T}}$ & + & - & - & - & - & - & - & + & - & - & - & + & + \\
\hline P. damselae subsp. piscicida ATCC $51736^{\mathrm{T}}$ & + & - & - & + & - & - & - & - & - & - & - & - & - \\
\hline P. iliopiscarium ATCC $51760^{\mathrm{T}}$ & + & - & - & - & - & - & - & + & + & - & - & - & + \\
\hline P. leiognathi ATCC $25521^{\mathrm{T}}$ & + & - & - & - & - & - & - & - & + & - & - & - & - \\
\hline P. phosphoreum ATCC $11040^{\mathrm{T}}$ & + & - & - & + & - & - & + & + & - & - & - & - & - \\
\hline V. aestuarianus ATCC $35048^{\mathrm{T}}$ & + & - & + & + & - & - & + & + & + & - & + & - & - \\
\hline V. alginolyticus ATCC $17749^{\mathrm{T}}$ & - & + & + & - & + & - & + & - & + & + & + & + & + \\
\hline V. anguillarum ATCC $19264^{\mathrm{T}}$ & + & - & + & - & + & - & - & + & + & - & + & + & - \\
\hline V. campbellii ATCC $25920^{\mathrm{T}}$ & - & - & + & - & + & + & + & - & - & - & - & + & + \\
\hline V. cincinnatiensis ATCC $35912^{\mathrm{T}}$ & - & + & - & + & - & + & - & - & + & - & + & - & ND \\
\hline V. cyclitrophicus ATCC $700982^{\mathrm{T}}$ & + & - & - & + & + & + & + & + & + & + & + & - & - \\
\hline V. fluvialis ATCC $33809^{\mathrm{T}}$ & + & - & + & - & + & + & + & + & + & + & + & - & - \\
\hline V. gazogenes ATCC $29988^{\mathrm{T}}$ & - & + & - & + & - & + & - & - & - & + & + & - & - \\
\hline V. harveyi ATCC $14126^{\mathrm{T}}$ & + & - & + & + & + & + & + & + & + & + & + & + & + \\
\hline V. ichthyoenteri ATCC $700023^{\mathrm{T}}$ & - & - & - & - & - & + & - & - & + & - & - & - & - \\
\hline V. lentus ATCC BAA- $539^{\mathrm{T}}$ & + & - & + & - & - & + & + & - & - & - & - & - & - \\
\hline V. mediterranei ATCC $43341^{\mathrm{T}}$ & + & - & + & + & + & + & + & + & - & + & + & - & - \\
\hline V. mimicus ATCC $33653^{\mathrm{T}}$ & - & + & + & - & + & - & + & + & + & - & - & - & + \\
\hline V. mytili ATCC $51288^{\mathrm{T}}$ & + & + & - & + & - & + & - & - & + & + & + & - & - \\
\hline V. natriegens ATCC $14048^{\mathrm{T}}$ & - & + & - & + & + & + & + & + & + & + & + & - & - \\
\hline V. navarrensis ATCC $51183^{\mathrm{T}}$ & - & - & + & - & + & + & + & - & + & + & + & + & - \\
\hline V. nereis ATCC $25917^{\mathrm{T}}$ & + & - & + & - & + & - & + & - & + & + & + & - & - \\
\hline V. nigripulchritudo ATCC $27043^{\mathrm{T}}$ & - & - & + & + & + & + & + & + & - & + & - & - & - \\
\hline V. ordalii ATCC $33509^{\mathrm{T}}$ & - & - & - & - & + & - & - & - & - & - & + & + & - \\
\hline V. orientalis ATCC $33934^{\mathrm{T}}$ & + & - & + & - & + & - & - & - & + & - & + & - & - \\
\hline V. parahaemolyticus ATCC $17802^{\mathrm{T}}$ & - & + & + & - & + & + & + & + & + & + & - & + & + \\
\hline V. pectenicida ATCC $700783^{\mathrm{T}}$ & + & - & - & - & - & - & - & - & - & - & - & + & - \\
\hline V. pelagius ATCC $25916^{\mathrm{T}}$ & - & - & - & + & + & + & - & + & + & + & + & - & - \\
\hline V. penaeicida ATCC $51841^{\mathrm{T}}$ & - & - & - & + & - & - & + & + & + & + & - & - & - \\
\hline V. proteolyticus ATCC $15338^{\mathrm{T}}$ & + & + & + & - & + & - & + & - & + & + & + & + & - \\
\hline V. rumoiensis LMG $20038^{\mathrm{T}}$ & + & + & - & - & + & - & + & + & + & - & + & - & - \\
\hline V. scophthalmi LMG $19158^{\mathrm{T}}$ & - & - & - & - & - & + & - & + & + & + & + & - & - \\
\hline V. splendidus ATCC $33125^{\mathrm{T}}$ & + & - & + & + & - & + & + & + & - & + & - & - & - \\
\hline V. tapetis LMG $19706^{\mathrm{T}}$ & - & - & - & - & - & - & + & - & - & - & - & - & - \\
\hline V. tasmaniensis LMG $20012^{\mathrm{T}}$ & + & - & + & - & - & + & - & - & + & - & - & - & - \\
\hline V. tubiashii ATCC $19109^{\mathrm{T}}$ & + & - & + & + & + & + & - & + & + & + & + & - & - \\
\hline V. vulnificus ATCC $27562^{\mathrm{T}}$ & - & - & + & + & - & + & + & + & + & + & - & - & + \\
\hline
\end{tabular}

The description is the same as that given for Vibrio salmonicida by Egidius et al. (1986) with the following additions. Negative for indole production and agarolysis. Resistant to carbenicillin $(100 \mu \mathrm{g})$ and ampicillin $(10 \mu \mathrm{g})$ and sensitive to novobiocin $(5 \mu \mathrm{g})$. The type strain is ATCC $43839^{\mathrm{T}}=$ CIP $103166^{\mathrm{T}}=$ LMG $14010^{\mathrm{T}}=$ NCIMB $2262^{\mathrm{T}}$.

\section{Description of Aliivibrio wodanis (Lunder et al. 2000) comb. nov.}

Basonym: Vibrio wodanis Lunder et al. 2000.

The description is the same as that given for Vibrio wodanis by Lunder et al. (2000) with the following additions. 
Sensitive to carbenicillin $(100 \mu \mathrm{g})$ and novobiocin $(5 \mu \mathrm{g})$. The type strain is ATCC BAA- $104^{\mathrm{T}}=$ NCIMB $13582^{\mathrm{T}}$ $=$ LMG $24053^{\mathrm{T}}$.

\section{Acknowledgements}

We thank Dr Natalie Moltschaniwskyj, School of Aquaculture, University of Tasmania, for providing specimens of Euprymna tasmanica. DNA sequencing was carried out by the staff of the University of Michigan Sequencing Core. This work was supported by grant DEB 0413441 from the National Science Foundation and by grant $01 / 628$ from the Fisheries Research \& Development Corporation in Australia.

\section{References}

Ast, J. C. \& Dunlap, P. V. (2005). Phylogenetic resolution and habitat specificity of members of the Photobacterium phosphoreum species group. Environ Microbiol 7, 1641-1654.

Bang, S. S., Baumann, P. \& Nealson, K. H. (1978). Phenotypic characterization of Photobacterium logei (sp. nov.), a species related to P. fischeri. Curr Microbiol 1, 285-288.

Baumann, L. \& Baumann, P. (1977). Biology of the marine enterobacteria: genera Beneckea and Photobacterium. Annu Rev Microbiol 31, 39-61.

Baumann, P., Baumann, L., Bang, S. S. \& Woolkalis, M. J. (1980). Reevaluation of the taxonomy of Vibrio, Beneckea, and Photobacterium: abolition of the genus Beneckea. Curr Microbiol 4, 127-132.

Beijerinck, M. W. (1889). Le Photobacterium luminosum, bactérie lumineuse de la Mer du Nord. Arch Neerl Sci Exactes Nat 23, 401-405 (in French).

Bryant, T. N. (1991). Software for the development and evaluation of probabilistic identification matrices. Comput Appl Biosci 7, 189-193.

Bryant, T. N. (2004). PIBWin - software for probabilistic identification. J Appl Microbiol 97, 1326-1327.

Carson, J., Higgins, M. J., Wilson, T. K., Gudkovs, N. \& Bryant, T. N. (2006). Aquatic Animal Health Subprogram. Vibrios of Aquatic Animals: Development of a National Standard Diagnostic Technology. Final report. Project 01/628. Hobart: Fisheries Research \& Development Corporation.

Duchaud, E., Rusniok, C., Frangeul, L., Buchrieser, C., Givaudan, A., Taourit, S., Bocs, S., Boursaux-Eude, C., Chandler, M. \& other authors (2003). The genome sequence of the entomopathogenic bacterium Photorhabdus luminescens. Nat Biotechnol 21, 1307-1313.

Egidius, E., Wiik, R., Andersen, K., Hoff, K. A. \& Hjeltnes, B. (1986). Vibrio salmonicida sp. nov., a new fish pathogen. Int J Syst Bacteriol 36, 518-520.

Farmer, J. J., III, Janda, J. M., Brenner, F. W., Cameron, D. N. \& Birkhead, K. M. (2005). Genus I. Vibrio Pacini 1854, $411^{\mathrm{AL}}$. In Bergey's Manual of Systematic Bacteriology, 2nd edn, vol. 2, part B, pp. 494546. Edited by D. J. Brenner, N. R. Krieg, J. T. Staley \& G. M. Garrity. New York: Springer.

Farris, J. S., Albert, V. A., Källersjö, M., Lipscomb, D. \& Kluge, A. G. (1996). Parsimony jackknifing outperforms neighbor-joining. Cladistics 12, 99-124.
Goloboff, P. A., Farris, J. S. \& Nixon, K. C. (2005). TNT: tree analysis using new technology. Version 1.0. http://www.zmuc.dk/public/ phylogeny/TNT/Read_Me!.htm

Graybeal, A. (1998). Is it better to add taxa or characters to a difficult phylogenetic problem? Syst Biol 47, 9-17.

Harwood, C. S., Bang, S. S., Baumann, P. \& Nealson, K. H. (1980). Photobacterium logei sp. nov., nom. rev.; Beneckea nereida sp. nov., nom. rev.; and Beneckea gazogenes sp. nov., nom. rev. Int J Syst Bacteriol 30, 655.

Hendrie, M., Hodgkiss, W. \& Shewan, J. M. (1970). The identification, taxonomy and classification of luminous bacteria. J Gen Microbiol 64, 151-169.

Hillis, D. M. (1998). Taxonomic sampling, phylogenetic accuracy, and investigator bias. Syst Biol 47, 3-8.

Huang, C. Y., Garcia, J. L., Patel, B. K., Cayol, J. L., Baresi, L. \& Mah, R. A. (2000). Salinivibrio costicola subsp. vallismortis subsp. nov., a halotolerant facultative anaerobe from Death Valley, and emended description of Salinivibrio costicola. Int J Syst Evol Microbiol 50, 615-622.

Lunder, T., Sørum, H., Holstad, G., Steigerwalt, A. G., Mowinckel, P. \& Brenner, D. J. (2000). Phenotypic and genotypic characterization of Vibrio viscosus sp. nov. and Vibrio wodanis sp. nov. isolated from Atlantic salmon (Salmo salar) with 'winter ulcer'. Int J Syst Evol Microbiol 50, 427-450.

Reichelt, J. L. \& Baumann, P. (1973). Taxonomy of the marine, luminous bacteria. Arch Microbiol 94, 283-330.

Ruby, E. G. \& Nealson, K. H. (1976). Symbiotic association of Photobacterium fischeri with the marine luminous fish Monocentris japonica, a model of symbiosis based on bacterial studies. Biol Bull 151, 574-586.

Ruby, E. G., Urbanowski, M., Campbell, J., Dunn, A., Faini, M., Gunsalus, R., Lostroh, P., Lupp, C., McCann, J. \& other authors (2005). Complete genome sequence of Vibrio fischeri: a symbiotic bacterium with pathogenic congeners. Proc Natl Acad Sci U S A 102, 3004-3009.

Swofford, D. L. (2003). PAUP ${ }^{\star}$ : Phylogenetic Analysis Using Parsimony (*and Other Methods), version 4.0B10. Sunderland, MA: Sinauer Associates.

Thompson, F. L., Hoste, B., Thompson, C. C., Goris, J., Gomez-Gil, B., Huys, L., De Vos, P. \& Swings, J. (2002). Enterovibrio norvegicus gen. nov., sp. nov., isolated from the gut of turbot (Scophthalmus maximus) larvae: a new member of the family Vibrionaceae. Int J Syst Evol Microbiol 52, 2015-2022.

Thompson, F. L., Gevers, D., Thompson, C. C., Dawyndt, P., Naser, S., Hoste, B., Munn, C. B. \& Swings, J. (2005). Phylogeny and molecular identification of vibrios on the basis of multilocus sequence analysis. Appl Environ Microbiol 71, 5107-5115.

Thyssen, A. \& Ollevier, F. (2005). Genus II. Photobacterium Beijerinck $1889,401^{\mathrm{AL}}$. In Bergey's Manual of Systematic Bacteriology, 2nd edn, vol. 2, part B, pp. 546-552. Edited by D. J. Brenner, N. R. Krieg, J. T. Staley \& G. M. Garrity. New York: Springer.

Varón, A., Vinh, L. S., Bomash, I. \& Wheeler, W. C. (2007). POY 4.0 Beta 1822. New York: American Museum of Natural History.

Wheeler, W. (1996). Optimization alignment: the end of multiple sequence alignment in phylogenetics? Cladistics 12, 1-9.

Willcox, W. R., Lapage, S. P., Bascomb, S. \& Curtis, M. A. (1973). Identification of bacteria by computer: theory and programming. J Gen Microbiol 77, 317-330. 